\title{
Insight into the impact of two structural calcium ions on the properties of Pleurotus eryngii versatile ligninolytic peroxidase
}

Yu Gao ${ }^{\mathrm{a}}$, Lanyan Zheng ${ }^{\mathrm{a}}$, Jian-Jun $\mathrm{Li}^{\mathrm{b}}$, Yuguang $\mathrm{Du}^{\mathrm{b}}$

${ }^{\mathrm{a} D e p a r t m e n t}$ of Microbiology and Parasitology, China Medical University, No.77 Puhe Road, Shenyang 110122, Liaoning Province, China

${ }^{\mathrm{b}}$ National Key Laboratory of Biochemical Engineering, National Engineering Research Center for Biotechnology (Beijing), Institute of Process Engineering, Chinese Academy of Sciences, No. 1 North 2nd Street, Beijing 100190, China

Corresponding authors: Email: lyzheng@mail.cmu.edu.cn, Phone: +86 2431939011 , Fax: +86 24 31939023; jjli@ipe.ac.cn, Phone: +86 108254 5039, Fax: +86 108254 5039; ygdu@ipe.ac.cn, Phone: +86 108254 5070, Fax: +86 1082545039

\section{Abstract}

Two structural $\mathrm{Ca}^{2+}$ (proximal and distal) is known to be important for ligninolytic peroxidases. However, few studies toward impact of residues involved in two $\mathrm{Ca}^{2+}$ on properties of ligninolytic peroxidases have been done, especially the proximal one. In this study, mutants of nine residues involved in liganding two $\mathrm{Ca}^{2+}$ of Pleurotus eryngii versatile peroxidase (VP) were investigated. Most mutants almost completely lost activities, except the mutants of proximal $\mathrm{Ca}^{2+}-\mathrm{S} 170 \mathrm{~A}$ and V192T. In comparison with WT (wild type), optimal pH values of S170A, S170D, and V192T shifted from $\mathrm{pH} 3.0$ to $\mathrm{pH} 3.5$. The order of thermal and $\mathrm{pH}$ stabilities of WT, V192T, S170A, and S170D is similar to that of their specific activities: WT > 
V192T > S170A > S170D. The CD (circular dichroism) results of WT and several mutants indicated that mutations had some effects on secondary structures. For the first time, it was observed that the thermostability of ligninolytic peroxidases is related with proximal $\mathrm{Ca}^{2+}$ too, and the mutant containing distal $\mathrm{Ca}^{2+}$ only was obtained. Our results clearly demonstrated that enzymatic activities, $\mathrm{pH}$ and thermal stabilities, $\mathrm{Ca}^{2+}$ content, and secondary structures of VP have close relationship with the residues involved in two structural $\mathrm{Ca}^{2+}$.

Key words

versatile peroxidase; structural calcium ion; site-directed mutagenesis; $\mathrm{pH}$ and thermal stability; secondary structure

\section{Introduction}

Rising energy consumption, depletion of fossil fuels and increasing environmental concerns have shifted the focus of energy generation towards biofuels derived from renewable sources. Lignocellulose, as a renewable organic material, consisting of cellulose, hemicellulose and lignin, is the major structural component of plants [1]. Lignin blocks enzymes to access cellulose and hemicellulose. To maximally utilize carbohydrates in the biomass, a pretreatment process is needed to improve accessibility to hydrolytic enzymes. From both economic and environmental perspectives, pretreatment with lignin-degrading microorganisms or enzymes has received renewed interest as an alternative to thermal/chemical pretreatment [2-4].

It's known that several oxidoreductases secreted by white-rot basidiomycetes are 
involved in lignin biodegradation, including laccase, lignin peroxidase (LiP), manganese peroxidase (MnP), and versatile peroxidase (VP) [1]. Among them, VP is arousing great interest due to its ability to oxidize a variety of substrates [1]. VP has been described in Pleurotus, Bjerkandera and some other basidiomycetes [5,6]. VP could not only oxidize the substrates that LiP, MnP, and CiP (Coprinopsis cinerea peroxidase) can oxidize like veratryl alcohol, $\mathrm{Mn}^{2+}$, and simple phenolic compounds, but also some high-redox-potential aromatic compounds which these three enzymes can't oxidize [1]. A lot of studies towards VP have been carried out, including heterologous overexpression $[8,9]$, enzymology $[5,8]$, site-directed mutagenesis $[9,10]$, and protein engineering for improved thermal and $\mathrm{H}_{2} \mathrm{O}_{2}$ stability [11-14].

VP's crystal structure has been published, contains a heme cofactor located inside an internal cavity, two $\mathrm{Ca}^{2+}$ binding regions, and a $\mathrm{Mn}^{2+}$ binding site, etc. (Fig. 1) [15]. According to the structure of VP, both calcium ions are coordinated by seven oxygen atoms, which is typical for $\mathrm{Ca}^{2+}$. One calcium ion was reported to be tightly bound on the proximal side of the heme, while the other one was bound on the distal side of heme and considered to be loosely bound [16]. Due to the relative proximity of the calcium ions to the heme, they were proposed to be important for stabilization of the active site of the enzyme. The residues involved in liganding two calcium ions are highly conserved among peroxidases (Fig. 1). It has been found that thermal inactivation of $\mathrm{MnP}$ and $\mathrm{LiP}$ resulted in loss of distal $\mathrm{Ca}^{2}$, whereas alkaline treatment of LiP leads to release both $\mathrm{Ca}^{2}$ [16-19]. Therefore, it appears that the distal $\mathrm{Ca}^{2+}$ binding region is related with the thermostability of ligninolytic peroxidases, and both 
have close relationship with the alkaline stability of ligninolytic peroxidases. Sutherland et al. investigated the role of Asp47 in MnP, one of the ligands of distal $\mathrm{Ca}^{2+}$. They found that the specific activity of D47A was less than $1 \%$ of that of WT $\mathrm{MnP}$, and D47A had only one $\mathrm{Ca}^{2+}$ and the same spectroscopic properties as thermally inactivated $\mathrm{MnP}[16]$. On the basis of the properties and structure of peanut peroxidase, Reading et al. engineered a disulfide bond near the distal calcium binding site of MnP by mutation of Ala48 and Ala63, and the double mutant MnP A48C/A63C was more stable against the effects of temperature and $\mathrm{pH}$ than WT[20]. This study suggested that reinforcing the local structure of the distal $\mathrm{Ca}^{2+}$ active site through a disulfide bond would increase enzyme stability.

So far, no systematic studies towards the residues involved in two $\mathrm{Ca}^{2+}$ binding pockets of ligninolytic peroxidases have been performed, those liganding the proximal calcium ion in particular. In this study, all residues participating in the two $\mathrm{Ca}^{2+}$ binding regions of Pleurotus eryngii VP were mutated respectively, and the effects of mutagenesis on specific activity, UV-vis spectroscopy, $\mathrm{pH}$ and thermal stability, $\mathrm{Ca}^{2+}$ contents, and secondary structure were studied.

\section{Materials and Methods}

\subsection{Materials}

Chemicals were from Sigma and Merck. Oligonucleotides were synthesized by Shanghai Sangon Biotech Co. Ltd (China). Pfu DNA polymerases from Fermentas. DpnI was from New England BioLabs. The plasmid Mini Kit I was from Omega 
Bio-tek, and Competent Cell Preparation Kit was from Takara Biotechnology. The nickel column was from Novagen.

\subsection{Bacterial strains, plasmids, media and DNA manipulations}

E. coli DH5 $\alpha$ was used for routine DNA transformation and plasmid isolation. $E$. coli BL21(DE3) was utilized for VP overexpression. E. coli strains were routinely grown in Luria-Bertani broth at $37^{\circ} \mathrm{C}$ with aeration or on LB supplemented with $1.5 \%$ (w/v) agar.

General molecular biology techniques were carried out by standard procedures [21].

\subsection{Construction of site-directed mutants, protein overexpression and purification}

All site-directed mutants were constructed according to the standard QuikChange Site-Directed Mutagenesis protocol using pET32a-VP as a template and the primers listed in Table S1 (Supporting Information) [8].

WT VP and mutants were overexpressed in E. coli BL21(DE3) in the presence of heme under IPTG induction and purified on Nickel column [8]. Proteins were concentrated, and the concentration was determined by the Bradford method using bovine serum albumin as a standard [21]

\subsection{Enzyme activity assay}
All
enzymatic
essays
against
ABTS
$\left(2,2^{\prime}\right.$-azinobis

(3-ethylbenzothiazoline-6-sulfonate) were done at $200 \mu$ scale in $0.1 \mathrm{M}$ sodium 
tartrate ( $\mathrm{pH} 3.5$ ) containing $0.1 \mathrm{mM} \mathrm{H}_{2} \mathrm{O}_{2}$ at $418 \mathrm{~nm}$ and $25^{\circ} \mathrm{C}$. The enzymatic activities against Reactive Black 5 (RB5), veratryl alcohol (VA), and $\mathrm{Mn}^{2+}$ were carried out following the published procedures [8]. One unit of enzyme activity (U) is defined as the amount of the enzyme that catalyzes conversion of $1 \mu \mathrm{mol}$ substrate per min. The $k_{m}$ and $v_{\max }$ values for ABTS were determined using Lineweaver-Burk plot. The $\mathrm{Rz}$ value equals to $\mathrm{A}_{407 \mathrm{~nm}} / \mathrm{A}_{280 \mathrm{~nm}}$.

\section{$2.5 U V$-vis spectroscopy}

UV-visible spectra for all mutants and WT VP were recorded between $250 \mathrm{~nm}$ and $550 \mathrm{~nm}$ in $10 \mathrm{mM}$ sodium tartrate $\left(\mathrm{pH} \mathrm{5.5)}\right.$ at $25^{\circ} \mathrm{C}$ on a multimode reader (Infinite M200 PRO, TECAN).

\subsection{Determination of optimal $\mathrm{pH}$ and $\mathrm{pH}$ stability}

The pH-rate profiles were determined using $0.5 \mathrm{mM}$ ABTS in $0.1 \mathrm{M} \mathrm{B} \mathrm{\&} \mathrm{R}$ (Britton and Robinson) buffer containing $0.1 \mathrm{mM} \mathrm{H}_{2} \mathrm{O}_{2}$ over the $\mathrm{pH}$ ranges of $\mathrm{pH} 2.0$ to 9.0 at $418 \mathrm{~nm}$ and $25^{\circ} \mathrm{C}$.

The $\mathrm{pH}$ stability assay was estimated by first preincubating the purified enzymes in $\mathrm{B} \& \mathrm{R}$ buffer at different $\mathrm{pH}$ values ( $\mathrm{pH} 2.0$ to 8.0 ) at $4^{\circ} \mathrm{C}$ for $1 \mathrm{~min}, 1 \mathrm{hr}, 4 \mathrm{hr}, 25$ $\mathrm{hr}$, and $120 \mathrm{hr}$ respectively. The residual activities were then measured by using 0.5 $\mathrm{mM}$ ABTS as the substrate in $0.1 \mathrm{M}$ sodium tartrate $(\mathrm{pH} 3.5)$ in the presence of 0.1 $\mathrm{mM} \mathrm{H} \mathrm{H}_{2} \mathrm{O}_{2}$ at $25^{\circ} \mathrm{C}$ immediately. For each enzyme, the highest activity was taken as $100 \%$, and the percentage of the residual activity at different time points and $\mathrm{pH}$ values against the highest one was calculated. 


\subsection{Determination of thermal stability}

The thermostabilities of WT and mutants were estimated by measuring the $\mathrm{T}_{50}$ values using 96-well gradient thermocyclers (TC-5000, TECHNE), which was defined as the temperature at which the enzyme loses $50 \%$ of original activity following incubation for $10 \mathrm{~min}$. After some trials, the enzymes were incubated for 10 min in a gradient temperature ranging from $40^{\circ} \mathrm{C}$ to $70^{\circ} \mathrm{C}$ for $\mathrm{WT} \mathrm{VP}, 35^{\circ} \mathrm{C}$ to $65^{\circ} \mathrm{C}$ for $\mathrm{V} 192 \mathrm{~T}, 23^{\circ} \mathrm{C}$ to $53^{\circ} \mathrm{C}$ for $\mathrm{S} 170 \mathrm{~A}$, and from $25^{\circ} \mathrm{C}$ to $55^{\circ} \mathrm{C}$ for $\mathrm{S} 170 \mathrm{D}$ respectively. After $10 \mathrm{~min}$ of incubation, samples were chilled on ice for $10 \mathrm{~min}$ and further incubated for $5 \mathrm{~min}$ at $\mathrm{rt}$. Afterwards aliquots $(50 \mu \mathrm{l})$ were subjected to the ABTS-based assay. The thermostability values were deduced from the ratio between the residual activities incubated at different temperature points and the initial activity at rt.

\subsection{Determination of calcium concentration in VP}

The amount of calcium in the VP samples was determined by inductively coupled plasma optical emission spectrometer (ICP-OES), Thermo Scientific iCAP6300.

The purified enzymes were first dialyzed against $10 \mathrm{mM}$ sodium tartrate $(\mathrm{pH}$ 5.5) supplemented with $1 \mathrm{mM} \mathrm{CaCl} 2$ and then against $10 \mathrm{mM}$ sodium tartrate ( $\mathrm{pH}$ 5.5). To

remove free $\mathrm{Ca}^{2+}$ further, the enzyme samples were again dialyzed against $10 \mathrm{mM}$ sodium tartrate ( $\mathrm{pH} 5.5$ ), which had been treated with Chelex 100 to remove free $\mathrm{Ca}^{2+}$ in buffer [22]. The enzyme samples were then loaded onto a Sephadex G-25 column $(2.5 \times 20 \mathrm{~cm})$, and the column was washed with $10 \mathrm{mM}$ sodium tartrate $(\mathrm{pH} 5.5)$ 
treated with Chelex 100 at a flow rate of $0.4 \mathrm{ml} / \mathrm{min}$. The enzyme solutions were then concentrated with Amicon (10 kDa cut-off) to about $3 \mathrm{ml}$, and $5 \mathrm{~mL}$ of nitric acid $(65 \%$ w/w) and $2 \mathrm{~mL}$ of $30 \%$ hydrogen peroxide were added. The vessels were immediately closed after adding the oxidants. The digestion was carried out at $130^{\circ} \mathrm{C}$ for $20 \mathrm{~min}$. The digestion products were then concentrated to dryness at $70^{\circ} \mathrm{C}$. Finally, the samples were brought to a volume of $10 \mathrm{~mL}$ by adding water.

\subsection{Circular Dichroism Spectroscopy}

Far-UV CD spectra (190 to $260 \mathrm{~nm})$ were recorded for protein samples $(0.2$ $\mathrm{mg} / \mathrm{ml}$ ) in $50 \mathrm{mM}$ citrate-phosphate buffer (pH 5.5) with a Jasco J-810 spectropolarimeter at $25^{\circ} \mathrm{C}$. Data was averaged over three runs and baselines were subtracted.

Secondary-structure analyses were performed with BeStSel method, which is available at the bestsel.elte.hu server [23]. Secondary structure elements were determined from the PDB (Protein Data Bank) structures using the DSSP (Dictionary of Secondary Structure of Proteins) algorithm for identification. Secondary structures of DSSP include: H, $\alpha$-helix; G, $3{ }_{10}$ helix; I, $\pi$-helix; E, $\beta$-strand; B, $\beta$-bridge; S, bend; T, turn; and "others". The components of DSSP, including irregular or loop or residues invisible in the 3D structure, are assigned as "others." [23]

\section{Results}

\subsection{Identification of the target residues for mutagenesis}


Based on the crystal structure of Pleurotus eryngii VP (PDB code: 2BOQ), the ligands of distal $\mathrm{Ca}^{2+}$ include the side chains (carboxylate or hydroxyl) of Asp48, Asp62, and Ser64, the oxygen atoms of the peptide bonds of Gly60 and Asp48, and two water molecules, and those of the proximal one consist of the side chains (hydroxyl or carboxylate) of Ser170, Asp187, Thr189, Asp194, and the oxygen atoms of the peptide bonds of Ser170, Thr189, and Val192 (Fig. 1). These residues are highly conserved among peroxidases, except variation at the residue 192 (see Supporting Information Fig. S1). All above residues were investigated in this study, and all mutations were confirmed by sequencing.

\subsection{Construction, overexpression and purification of site-directed mutants}

To investigate the impact of the polar side chains of the residues involved in coordinating two structural calcium ions on enzyme properties, Asp48, Asp62, Ser64, Ser170, Asp187, Thr189, and Asp194 were mutated into Ala with the hydrophobic methyl group, and Ser170 was also mutated into Asp containing the polar side chain for comparison. Gly60 and Val192, which coordinate the calcium ions through the oxygen atoms of the peptide bonds rather than the side chains, were replaced with Ser and Thr containing the polar hydroxyl group respectively. Site-directed mutants were constructed using WT construct pET32a-VP as the template. All mutants were overexpressed in E. coli BL21(DE3), and purified on nickel column (Supporting Information Fig. S2).

\subsection{Spectroscopic studies}


UV-visible spectra for WT VP, S170D, and S170A were recorded between 250 $\mathrm{nm}$ and $700 \mathrm{~nm}$ (Fig. 2, Supporting Information Fig. S3), and those for other mutants were scanned between $250 \mathrm{~nm}$ and $550 \mathrm{~nm}$ (Fig. 2, Supporting Information Fig. S4). No obvious peak was observed around $500 \mathrm{~nm}$ (corresponding to CT2 band, charge transfer band) for WT, and three peaks at $536 \mathrm{~nm}, 564 \mathrm{~nm}$, and $636 \mathrm{~nm}$ were seen, which were ascribed to $\beta, \alpha$, and CT1 bands respectively (see Supporting Information Fig. S5) [13,15,24]. Similar results were obtained for S170A and S170D (see Supporting Information Fig. S3, S5). An obvious shoulder at around $360 \mathrm{~nm}$ was observed in D48A, G60S, S170A, D187A, T189A, and D194A. A slight red shift (around $5 \mathrm{~nm}$ ) was seen in the Soret band in the mutants D48A, G60S, D62A, S64A, S170D, and V192T. A clear increase at $532 \mathrm{~nm}$ was found in D48A, G60S, D62A, and S64A. The Soret peak became wider in D48A, G60S, S170A, D187A, T189A, and D194A due to the appearance of the shoulder at $360 \mathrm{~nm}$.

\subsection{Enzymatic activities of wild-type VP and mutants}

The specific activities of WT VP and mutants against ABTS are shown in Table 1. Compared with WT, most mutations lead to greatly reduced activities except S170A and V192T, and the specific activities of most mutants lost $>98 \%$ of that of WT, implying that these amino acids are crucial for VP to maintain activity. The specific activities of S170A and V192T were much higher than the other mutants, and reduced to $23 \%$ and $39 \%$ of that of WT respectively. Unexpectedly, S170D displayed much lower activity than S170A. 
In order to see whether the mutations led to different impact on enzyme activity towards other substrates, the mutants D48A, S170A, D187A, and V192T were chosen to determine their specific activities against RB5, veratryl alcohol (VA), and $\mathrm{Mn}^{2+}$ (Table 1). The trends of the variants towards different substrates were similar to that when ABTS was used as the substrate, though the different effects towards different substrates were observed. D48A and D187A showed greatly reduced activity towards RB5, VA, and $\mathrm{Mn}^{2+}$. S170A and V192T exhibited very low activity for RB5 and VA, and retained slightly higher activity against $\mathrm{Mn}^{2+}$.

Most mutants' specific activities were so low that their steady-state kinetics couldn't be measured. Therefore, only the kinetic parameters of WT VP, S170A, S170D, and V192T were determined (Table 2). Compared with the $K_{m}$ value of WT, those of S170A and V192T were not affected too much, whereas that of S170D was increased by 3.2-fold. In comparison with WT, the $k_{\text {cat }}$ values and the catalytic efficiencies $\left(k_{\mathrm{cat}} / K_{m}\right)$ of S170A, S170D, and V192T were significantly reduced, especially the catalytic efficiency of S170D with 182.6-fold decrease.

\section{5 pH optima and stabilities of WT VP and mutants}

Britton-Robinson buffer ( $\mathrm{B} \& \mathrm{R}$ buffer) is a "universal" $\mathrm{pH}$ buffer used for the range $\mathrm{pH} 2$ to $\mathrm{pH} 12$, so $\mathrm{B} \& \mathrm{R}$ buffer was chosen for determination of optimal $\mathrm{pH}$ and $\mathrm{pH}$ stability assay. The $\mathrm{pH}$-activity profiles for WT VP, S170A, S170D, and V192T were determined over the $\mathrm{pH}$ ranges 2.0 - 8.0. The optimal $\mathrm{pH}$ of WT VP was at $\mathrm{pH} 3.0$ as reported [11], while that value shifted to 3.5 for three mutants (see 
Supporting Information Fig. S4). All enzymes showed higher activities over a narrow $\mathrm{pH}$ range. As shown in Fig. S3, when $\mathrm{pH}$ is above 6.0 or at 2.0 , all enzymes nearly completely lost activity except S170D.

The $\mathrm{pH}$ stabilities of WT, S170A, S170D, and V192T over the $\mathrm{pH}$ ranges 2.0 8.0 were also measured (Fig. 3). At pH 2.0, 8.0, and 9.0, all enzymes were almost completely inactivated after one hour. Just as reported [11], WT VP remained relatively stable in the $\mathrm{pH}$ ranges $3.5-7.0$, retaining $70 \%$ to $90 \%$ of initial activity after $120 \mathrm{hr}$. The $\mathrm{pH}$ stabilities of four enzymes followed the order of WT > V192T > S170A > S170D, showing a similar trend to the specific activities. S170D, exhibiting the lowest $\mathrm{pH}$ stability, completely lost activity over the $\mathrm{pH}$ ranges 2.0 to 8.0 after 1 hr.

\subsection{Thermal stability studies}

$\mathrm{T}_{50}$ was used to estimate the thermostabilities of WT and S170A, S170D, and V192T (Fig. 4). $\mathrm{T}_{50}$ was approximately $59^{\circ} \mathrm{C}$ for WT VP, $54^{\circ} \mathrm{C}$ for $\mathrm{V} 192 \mathrm{~T}, 44^{\circ} \mathrm{C}$ for S170A, and $32^{\circ} \mathrm{C}$ for S170D. Therefore, the thermostability followed the order by WT $>$ V192T $>$ S170A $>$ S170D. S170D exhibited the lowest thermostability.

\subsection{Determination of calcium concentration in VP}

In order to correlate the enzymatic activity of VP with the contents of $\mathrm{Ca}^{2+}$, the calcium concentrations of WT and the representative mutants D48A, S170A, and D187A were determined by ICP-OES (Table 3). The results (in $\mathrm{mol} \mathrm{Ca}^{2+} /$ mol protein) are as follows: 1.9 for VP WT, 1.5 for S170A, 1.1 for D48A, and 0.7 for D187A. 


\subsection{Circular dichroism (CD) for WT VP and several mutants}

$\mathrm{CD}$ was used to investigate the effects of mutations on the conformational or structural changes. Since the tartrate buffer $(10 \mathrm{mM}, \mathrm{pH} 5.5)$ used for protein storage has a strong background between $190 \mathrm{~nm}$ and $250 \mathrm{~nm}$ (see Supporting Information Fig. S7), so the tartrate buffer was replaced with the citrate-phosphate buffer ( $50 \mathrm{mM}$, pH 5.5). D48A, D187A, S170A, and S170D showed different CD spectra and secondary structures from WT VP, D187A in particular (Fig. 5, Table 4). D48A and S170A exhibited similar secondary structures. The results indicated that mutations had some effects on protein conformation or secondary structure.

\section{Discussion}

Lignin removal is one of the main limiting factors that lead to high production cost of lignocelluloses-based products. High-redox-potential ligninolytic peroxidases are important for that process. VP, as a type of newly discovered high-redox-potential ligninolytic peroxidase, received great interest due to catalytic promiscuity [1]. The structure-function relationship of VP has been well studied [9,10,12-14]. However, few studies toward the relationship between structure and the thermal/pH stability of VP have been done.

In the current study, we focus on the impact of the residues involved in two $\mathrm{Ca}^{2+}$ binding sites of VP on specific activity, UV-vis spectroscopy, the thermal and $\mathrm{pH}$ stability, $\mathrm{Ca}^{2+}$ concentration, and secondary structure. Ten site-directed mutants of VP were constructed and characterized. 
A red shift in the Soret peak from 407 to $412 \mathrm{~nm}$ and an obvious absorption peak at $360 \mathrm{~nm}$ were seen in some mutants. An increase at $532 \mathrm{~nm}$ was found only in the mutants of the residues liganding the distal calcium ion. It appears that mutations of the residues from two $\mathrm{Ca}^{2+}$ binding sites had different effects on $\mathrm{UV}$-vis spectroscopy. The shoulder at $360 \mathrm{~nm}$, which has been observed in many low-spin iron (III) species, coupled with the red shift of the Soret absorbance and the peak at $532 \mathrm{~nm}$ in some mutants, suggested that the heme iron had formed a low-spin hexacoordinate complex, as was shown previously for MnP D47A and thermally inactivated MnP and LiP $[16,20,24]$.

Compared with WT VP, the optimal pH values of S170A, S170D, and V192T shifted from $\mathrm{pH} 3.0$ to $\mathrm{pH} 3.5$. The similar shift was also found in some other mutants [11]. However, the $\mathrm{pH}$ stabilities of all mutants were significantly dropped. The order of the $\mathrm{pH}$ stabilities of WT, V192T, S170A, and S170D is similar to that of their specific activities. Just like pH stability, the order of the thermostabilities of WT, V192T, S170A, and S170D is similar to that of their specific activities. These results confirmed that the $\mathrm{pH}$ and thermal stabilities of VP are closely related with the residues liganding proximal $\mathrm{Ca}^{2+}$ and the $\mathrm{Ca}^{2+}$ contents (Table 3). For the first time, it was observed that the thermostability of ligninolytic peroxidases such as VP is also related with proximal $\mathrm{Ca}^{2+}[17]$. Unfortunately, no mutants of the distal $\mathrm{Ca}^{2+}$ binding site could be thermally characterized for comparison due to greatly lowered activity as reported [16].

Two structural calcium ions are important for maintaining the integrity of the 
heme environment of ligninolytic peroxidases. During thermal inactivation of LiP and $\mathrm{MnP}$, only the more weakly-bound distal $\mathrm{Ca}^{2+}$ is thought to dissociate [17-19]. Both calcium ions were removed during alkaline treatment of LiP [17].However, it seems that the role of $\mathrm{Ca}^{2+}$ in other peroxidases may be different from that in the high-redox-potential peroxidases LiP, MnP, and VP. When two calcium ions were completely removed from horseradish and peanut peroxidases, the enzymes were still $40 \%$ and $50 \%$ active, respectively [25-27].In contrast, even when only one $\mathrm{Ca}^{2+}$ was released from LiP and MnP [16-20], the enzymes almost completely lost activities. In the case of VP, D48A and D187A roughly contain one mol $\mathrm{Ca}^{2+} / \mathrm{mol}$ protein, and both mutations led to nearly complete loss of activities. The result of D48A is similar to that of D47A of MnP, and the mutant containing distal $\mathrm{Ca}^{2+}$ only was obtained for the first time [16]. S170A has higher $\mathrm{Ca}^{2+}$ content than D187A and D48A, but lower than WT VP, and it retained about $23 \%$ of WT VP activity. The results of S170A suggested that proximal $\mathrm{Ca}^{2+}$ could be still loosely bound in S170A, and some S170A proteins still contained two $\mathrm{Ca}^{2+}$, whereas some had only one. Though the $\mathrm{Ca}^{2+}$ concentrations were not determined for other mutants, according to their activities, it might be predicted that the mutants which almost completely lost activities such as G60S, D62A, S64A, S170D, T187A, and D194A would contain only one mol Ca ${ }^{2+}$ (proximal or distal)/mol protein, and the $\mathrm{Ca}^{2+}$ content of V192T would be, just like S170A, between $1-2 \mathrm{~mol} \mathrm{Ca} \mathrm{Ca}^{2+} / \mathrm{mol}$ protein. These results demonstrated that mutation of the residues involved in two $\mathrm{Ca}^{2+}$ led to great change in the contents of $\mathrm{Ca}^{2+}$, resulting in big effect on VP activity and other properties, and enzyme activity of VP has close 
relationship with the residues involved in two structural $\mathrm{Ca}^{2+}$ and the amount of calcium in VP. Comparison of the crystal structures of peanut peroxidase (PNP) (PDB code: $1 \mathrm{SCH}$ ) and VP revealed that the distal calcium binding site of PNP had some unique characteristics. Distal $\mathrm{Ca}^{2+}$ was liganded by amino acids and one water molecule, instead of two water ligands like VP, which might explain why the rigorous conditions were required to release $\mathrm{Ca}^{2+}$ from PNP [16,27]. In addition, close to the calcium ligands, Asp43 and Asp50, there was a disulfide bond between Cys44 and Cys49 that formed a short loop (see Supporting Information Fig. S8) [27]. In VP, this loop was much longer and did not have a disulfide bond, and the residues corresponding to Cys44 and Cys49 of PNP are Ala49 and Ala61 of VP respectively (see Supporting Information Fig. S1, Fig. S8). This additional disulfide bond may be the reason why the heme environment and activity of PNP was not affected as significantly as VP, LiP, and MnP upon the loss of calcium. This has been proved by engineering such a disulfide bond in $\mathrm{MnP}$ to enhance the thermal and $\mathrm{pH}$ stability [20].

In comparison with WT VP, most mutants exhibited greatly reduced activities, suggesting that these residues are essential for VP. It appears that the residues, whose two mutants (S170A and V192T) retained some activities, are mainly involved in the proximal $\mathrm{Ca}^{2+}$ binding region. Since it is the oxygen atom of the peptide bond of Gly60 coordinating distal $\mathrm{Ca}^{2+}$, mutation of Gly60 into Ser wouldn't have big effect on enzymatic activity. Unexpectedly, G60S showed significantly lower activity than WT. Close inspection of the residues around Gly60, the side chain (hydroxyl) of 
G60S might form ahydrogen bond with the oxygen atom of the amide bond of Leu268 according to the possible orientation of the side chain of G60S predicted by PyMOL (see Supporting Information Fig. S9). Given the fact that G60S nearly completely lost activity and it might contain only one mol $\mathrm{Ca}^{2+} / \mathrm{mol}$ protein, the newly formed hydrogen bond might greatly affect the coordination environment of distal $\mathrm{Ca}^{2+}$ of G60S. As far as the surrounding of Val192 is concerned, its hydrophobic side chain is rightly located on the surface of the protein (see Supporting Information Fig. S10). According to the predicted orientation for the side chain of V192T by PyMOL, it is very similar to that of Val192 (see Supporting Information Fig. S11). Thus, when it is replaced by Thr, the polar side chain (hydroxyl) of Thr may interact with water. Taking consideration into the specific activity and the possible $\mathrm{Ca}^{2+}$ content (between 1-2 mol $\mathrm{Ca}^{2+} / \mathrm{mol}$ protein) of $\mathrm{V} 192 \mathrm{~T}$, that interaction might not be so strong that coordination of proximal $\mathrm{Ca}^{2+}$ was not affected too much. Moreover, it's interesting to observe that there is a big difference (by two orders of magnitude) in $k_{\text {cat }}$ between S170D and S170A. Based on all information we obtained, mutations of Ser170 into Ala and Asp had no big impact on UV-vis (see Supporting Information Fig. S3, S5), but great influence on CD (see Supporting Information Fig. S12), calcium contents and activity. S170D and S170A were further inspected by predicting the orientations of their side chains PyMOL. Based on the predicted orientation of the side chain of S170D, it could possibly form a hydrogen bond with the oxygen atom of the peptide bond of Asp194 (see Supporting Information Fig. S13). Considering that S170D might contain only one mol $\mathrm{Ca}^{2+} / \mathrm{mol}$ protein, that hydrogen bond might have great 
impact on coordination of the proximal $\mathrm{Ca}^{2+}$, and the activity of S170D would be greatly affected. In the case of S170A, though the predicted orientation of the side chain (methyl) of S170A is similar to Ser170 (see Supporting Information Fig. S14), the additional hydroxyl group of Ser could make some difference. Given the relative activity and the $\mathrm{Ca}^{2+}$ concentration of $\mathrm{S} 170 \mathrm{~A}$, while it is replaced by Ala, the liganding environment of proximal $\mathrm{Ca}^{2+}$ was affected to some extent. It seems that the different properties (hydrophobic for methyl, hydrophilic for carboxylate) and the orientation of the side chains of Ala and Asp impacted coordination of proximal $\mathrm{Ca}^{2+}$ differently, and the greatly affected the liganding environment of proximal $\mathrm{Ca}^{2+}$ possibly led to significant influence on CD spectra, calcium contents and activities of S170A and S170D.

All in all, mutation of the residues involved in two structural $\mathrm{Ca}^{2+}$ influenced coordination of the proximal $\mathrm{Ca}^{2+}$ differently, leading to different impact on the $\mathrm{Ca}^{2+}$ contents of the mutants, and finally their activities and other properties such as UV-vis and CD were affected to different extent. Solving the crystal structures of some mutants such as V192A, S170D, and S170A might help to understand their different performance.

\section{Conclusion}

Ten mutants of the residues liganding two structural calcium ions of VP were made and fully characterized. Most mutations resulted in great loss of enzyme activity. The different impact of residues involved in two calcium ions on enzyme activity, 
UV-vis spectroscopy, and secondary structure was observed, and the effects of the mutants related to proximal $\mathrm{Ca}^{2+}$ only on enzyme activity, UV-vis spectroscopy, $\mathrm{pH}$ and thermal stability, and circular dichroism were presented for the first time. It was observed that the thermostability of ligninolytic peroxidases such as VP is related with

proximal $\mathrm{Ca}^{2+}$ for the first time as well. Our results confirmed the significance of residues coordinating two structural calcium ions of ligninolytic peroxidases and close relationship between enzyme activity and $\mathrm{Ca}^{2+}$ concentration in protein, and would provide a guide for engineering them towards higher thermal and $\mathrm{pH}$ stability.

\section{Acknowledgements}

We are grateful to National Science Foundation of China (31170765 and 31370799) and Beijing Natural Science Foundation (5162022) for the financial support.

\section{References}

[1] F.J. Ruiz-Dueňas, Á.T. Martínez, Microbial degradation of lignin: how a bulky recalcitrant polymer is efficiently recycled in nature and how we can take advantage of this, Microb. Biotechnol. 2 (2009)164-177.

[2] X.-F. Tian, Z. Fang, F. Guo, Impact and prospective of fungal pre-treatment of lignocellulosic biomass for enzymatic hydrolysis, Biofpr. 6 (2012) 335-350.

[3] C. Wan, Y. Li, Fungal pretreatment of lignocellulosic biomass, Biotechnol. Adv. 30 (2012) 1447-1457.

[4] A.D. Moreno, D. Ibarra, P. Alvira, E. Tomás-Pejó, M. Ballesteros, A review of 
biological delignification and detoxification methods for lignocellulosic bioethanol production, Crit. Rev. Biotechnol. 35 (2015) 342-354.

[5] M.J. Martínez, F.J.Ruiz-Dueňas, F. Guillén, A.T. Martínez, Purification and catalytic properties of two manganese peroxidase isoenzymes from Pleurotus eryngii, Eur. J. Biochem. 237 (1996) 424-432.

[6] T. Mester, J.A. Field, Characterization of a novel manganese peroxidase-lignin peroxidase hybrid isozyme produced by Bjerkandera species strain BOS55 in the absence of manganese, J. Biol. Chem. 273 (1998) 15412-15417.

[7] M. Pérez-Boada, W.A. Doyle, F.J. Ruiz-Dueňas, M.J. Martínez, A.T. Martínez, A.T. Smith, Expression of Pleurotus eryngii versatile peroxidase in Escherichia coli and optimisation of in vitro folding, Enzyme Microb. Tech. 30 (2002) $518-524$.

[8] X. Bao, A. Liu, X. Lu, J.-J. Li, Direct overexpression, characterization and $\mathrm{H}_{2} \mathrm{O}_{2}$ stability study of active Pleurotus eryngii versatile peroxidase in Escherichia coli, Biotechnol. Lett. 34 (2012) 1537-1543.

[9] F.J. Ruiz-Dueňas, M. Morales, M. Pérez-Boada, T. Choinowski, M.J. Martínez, K. Piontek, A.T. Martínez, Manganese oxidation site in Pleurotus eryngii versatile peroxidase: a site-directed mutagenesis, kinetic, and crystallographic study, Biochemistry 46 (2007) 66-77.

[10] F.J. Ruiz-Dueňas, M. Morales, M.J. Mate, A. Romero, M.J. Martínez, A.T. Smith, A.T. Martínez, Site-directed mutagenesis of the catalytic tryptophan environment in Pleurotus eryngii versatile peroxidase, Biochemistry 47 (2008) 
$1685-1689$.

[11] E. Garcia-Ruiz, D. Gonzalez-Perez, F.J. Ruiz-Dueňas, Á.T. Martínez, M. Alcalde, Directed evolution of a temperature-, peroxide- and alkaline $\mathrm{pH}$ tolerant versatile peroxidase, Biochem. J. 441 (2012) 487-498.

[12] X. Bao, X. Huang, X. Lu, J.-J. Li, Improvement of hydrogen peroxide stability of Pleurotus eryngii versatile ligninolytic peroxidase by rational protein engineering, Enzyme Microb. Tech. 54 (2014) 51-58.

[13] V. Sáez-Jiménez, S. Acebes, V. Guallar, A.T. Martínez, F.J. Ruiz-Dueñas, Improving the oxidative stability of a high redox potential fungal peroxidase by rational design, PLoS One 10 (2015) e0124750.

[14] D. Gonzalez-Perez, E. Garcia-Ruiz, F.J. Ruiz-Dueñas, A.T. Martinez, M. Alcalde, Structural determinants of oxidative stabilization in an evolved versatile peroxidase, ACS Catal. 4 (2014) 3891-3901.

[15] M. Pérez-Boada, F.J. Ruiz-Dueňas, R. Pogni, R. Basosi, T. Choinowski, M.J. Martínez, K. Piontek, Á.T. Martínez, Versatile peroxidase oxidation of high potential aromatic compounds: site-directed mutagenesis, spectroscopic and crystallographic investigation of three long-range electron transfer pathways, J. Mol. Biol. 345 (2005) 385-402.

[16] G.R.J. Sutherland, L.S. Zapanta, M. Tien, S.D. Aust, Role of calcium in maintaining the heme environment of manganese peroxidase, Biochemistry 36 (1997) 3654-3662.

[17] S.J. George, M. Kvaratskhelia, M.J. Dilworth, R.N.F. Thorneley, Reversible 
alkaline inactivation of lignin peroxidase involves the release of both the distal and proximal site calcium ions and bishistidine co-ordination of the haem, Biochem. J. 344 (1999) 237-244.

[18] G.R.J. Sutherland, S.D. Aust, The effects of calcium on the thermal stability and activity of manganese peroxidase, Arch. Biochem. Biophys. 332 (1996) $128-134$.

[19] G. Nie, S.D. Aust, Effect of calcium on the reversible thermal inactivation of lignin peroxidase, Arch. Biochem. Biophys. 337 (1997) 225-231.

[20] N.S. Reading, S.D. Aust, Engineering a disulfide bond in recombinant manganese peroxidase results in increased thermostability, Biotechnol. Prog. 16 (2000) 326-333.

[21] J. Sambrook, E.F. Fritsch, T. Maniatis, Molecular Cloning: A Laboratory Manual, Cold Spring Harbor, Cold Spring Harbor Laboratory Press, 1989.

[22] S.J. Lin, E. Yoshimura, H. Sakai, T. Wakagi, H. Matsuzawa, Weakly bound calcium ions involved in the thermostability of aqualysin I, a heat-stable subtilisin-type protease of Thermus aquaticus YT-1, Biochim. Biophys. Acta 1433 (1999) 132-138.

[23] A. Micsonai, F. Wien, L. Kernya, Y.-H. Lee, Y. Goto, M. Réfrégiers, J. Kardos, Accurate secondary structure prediction and fold recognition for circular dichroism spectroscopy, Proc. Natl. Acad. Sci. USA 112 (2015) E3095-E3103

[24] J. Verdín, R. Pogni, A. Baeza, M.C. Baratto, R. Basosi, R, Vázquez-Duhalt, Mechanism of versatile peroxidase inactivation by $\mathrm{Ca}^{2+}$ depletion, Biophysical. 
Chemistry 121 (2006) 163-170.

[25] Y. Shiro, M. Kurono, I. Morishima, Presence of endogenous calcium ion and its functional and structural regulation in horseradish peroxidase, J. Biol. Chem. 261 (1986) 9382-9390.

[26] C. Hu, D. Lee, R.N. Chibbar, R.B. van Huystee, $\mathrm{Ca}^{2+}$ and peroxidase derived from cultured peanut cells, Physiol. Plant 70 (1987) 99-102.

[27] D.J. Schuller, N. Ban, R.B. van Huystee, A. McPherson, T.L. Poulos, The crystal structure of peanut peroxidase, Structure 4 (1996) 311-321. 
Table 1. The specific activities of WT VP and mutants. Assay conditions are described in Materials and Methods. NA, no activity.

\begin{tabular}{|c|c|c|c|c|c|}
\hline \multirow{2}{*}{ Variants } & \multirow{2}{*}{$\mathrm{R}_{\mathrm{z}}$} & \multicolumn{4}{|c|}{ Specific activity (\%) } \\
\hline & & ABTS & RB5 & VA & $\mathrm{Mn}^{2+}$ \\
\hline WT & 0.67 & 100 & 100 & 100 & 100 \\
\hline D48A & 0.79 & 0.04 & NA & NA & 1.3 \\
\hline G60S & 0.84 & 0.80 & NA & NA & NA \\
\hline D62A & 0.89 & 0.11 & NA & NA & NA \\
\hline S64A & 0.73 & 0.07 & NA & NA & NA \\
\hline S170A & 1.16 & 23.1 & 4.5 & 5.7 & 77.1 \\
\hline S170D & 0.73 & 1.73 & NA & NA & NA \\
\hline D187A & 1.09 & 0.05 & NA & NA & 6.7 \\
\hline T189A & 1.14 & 0.18 & NA & NA & NA \\
\hline V192T & 0.55 & 39.3 & 13.6 & 11.3 & 28.2 \\
\hline D194A & 1.18 & 0.07 & NA & NA & NA \\
\hline
\end{tabular}


Table 2. Kinetic parameters of WT VP and mutants. Assay conditions are described in Materials and Methods, and ABTS was used as the substrate.

\begin{tabular}{cccc}
\hline & $K_{\mathrm{m}}(\mu \mathrm{M})$ & $k_{\mathrm{cat}}\left(\mathrm{s}^{-1}\right)$ & $k_{\mathrm{cat}} / K_{\mathrm{m}}\left(\mathrm{s}^{-1} \mu \mathrm{M}^{-1}\right)$ \\
\hline WT & $1.26 \pm 0.1$ & $0.53 \pm 0.02$ & 0.42 \\
$\mathrm{~S} 170 \mathrm{~A}$ & $1.11 \pm 0.07$ & $0.12 \pm 0.002$ & 0.11 \\
$\mathrm{~S} 170 \mathrm{D}$ & $3.98 \pm 0.47$ & $0.009 \pm 0.003$ & 0.0023 \\
$\mathrm{~V} 192 \mathrm{~T}$ & $0.85 \pm 0.0$ & $0.21 \pm 0.005$ & 0.25 \\
\hline
\end{tabular}


Table 3. Amount of $\mathrm{Ca}^{2+}$ in WT VP and three representative mutants. The amount of calcium in the VP samples was determined by inductively coupled plasma optical emission spectrometer (ICP-OES) as described in Materials and Methods.

\begin{tabular}{lll}
\hline & mol of $\mathrm{Ca}^{2+} / \mathrm{mol}$ of VP & Relative activity (\%) \\
\hline VP & $1.90 \pm 0.2$ & 100 \\
D48A & $1.1 \pm 0.1$ & 0.04 \\
D187A & $0.7 \pm 0.1$ & 0.05 \\
S170A & $1.5 \pm 0.2$ & 23.1 \\
\hline
\end{tabular}


Table 4. Secondary structure (\%) estimation based on CD spectra of WT VP and mutants. Secondary-structure analyses were performed with BeStSel method [23].

\begin{tabular}{|c|c|c|c|c|c|}
\hline & \multirow{2}{*}{$\alpha$ Helix } & \multicolumn{2}{|c|}{$\beta$ Strand } & \multirow{2}{*}{ Turn } & \multirow{2}{*}{ Others } \\
\hline & & Antiparallel & Parallel & & \\
\hline WT & 11.4 & 21.6 & 12 & 13.5 & 41.5 \\
\hline D48A & 21.1 & 6.0 & 7.6 & 15.8 & 49.4 \\
\hline S170A & 24.1 & 3.7 & 6.8 & 12.5 & 52.7 \\
\hline S170D & 18.3 & 21.2 & 11.2 & 13.5 & 35.9 \\
\hline D187A & 29.6 & 33.1 & 7.7 & 7.8 & 21.8 \\
\hline
\end{tabular}


Figure Captions

Fig. 1. Crystal structure of VP from Pleurotus eryngii (PDB code: 2BOQ) (a) and two "zoom-in" images of the distal (b) and proximal calcium active sites (c). The residues coordinating two structural calcium ions were labelled.

Fig. 2. UV-Vis spectra of wild-type VP and mutants. UV-visible spectra for all mutants and WT VP were scanned between $250 \mathrm{~nm}$ and $550 \mathrm{~nm}$ in $10 \mathrm{mM}$ sodium tartrate $(\mathrm{pH} 5.5)$.

Fig. 3. pH stabilities of WT VP and three mutants. a: WT. b: S170A. c: V192T. d: S170D. The $\mathrm{pH}$ stability was estimated by first preincubating the purified enzymes in B \& R (Britton and Robinson) buffer at different $\mathrm{pH}$ values ( $\mathrm{pH} 2.0$ to 9.0). Then the residual activities were estimated using $0.5 \mathrm{mM}$ ABTS in $0.1 \mathrm{M}$ sodium tartrate $(\mathrm{pH}$ 3.5) containing $0.1 \mathrm{mM} \mathrm{H}_{2} \mathrm{O}_{2}$ at $25^{\circ} \mathrm{C}$ immediately after incubation at $4^{\circ} \mathrm{C}$ for $1 \mathrm{~min}$, $1 \mathrm{hr}, 4 \mathrm{hr}, 25 \mathrm{hr}$, and $120 \mathrm{hr}$ respectively.

Fig. 4. Thermostabilities of wild-type VP and some mutants. Each point, including the standard deviation, was from three independent experiments. The enzymes were incubated for $10 \mathrm{~min}$ in a gradient temperature ranging from $40^{\circ} \mathrm{C}$ to $70^{\circ} \mathrm{C}$ for $\mathrm{WT} \mathrm{VP}$, $35^{\circ} \mathrm{C}$ to $65^{\circ} \mathrm{C}$ for $\mathrm{V} 192 \mathrm{~T}, 23^{\circ} \mathrm{C}$ to $53^{\circ} \mathrm{C}$ for $\mathrm{S} 170 \mathrm{~A}$, and $25^{\circ} \mathrm{C}$ to $55^{\circ} \mathrm{C}$ for $\mathrm{S} 170 \mathrm{D}$ respectively. After $10 \mathrm{~min}$ of incubation, samples were chilled on ice for $10 \mathrm{~min}$ and further incubated for $5 \mathrm{~min}$ at rt. Afterwards aliquots $(50 \mu \mathrm{l})$ were subjected to the ABTS-based assay.

Fig. 5. Circular dichroism (CD) spectra of WT VP and several representative mutants. Far-UV CD spectra (190 to $260 \mathrm{~nm})$ were recorded for protein samples $(0.2 \mathrm{mg} / \mathrm{ml})$ in $50 \mathrm{mM}$ citrate-phosphate buffer ( $\mathrm{pH} 5.5)$ at $25^{\circ} \mathrm{C}$. 
Fig. 1
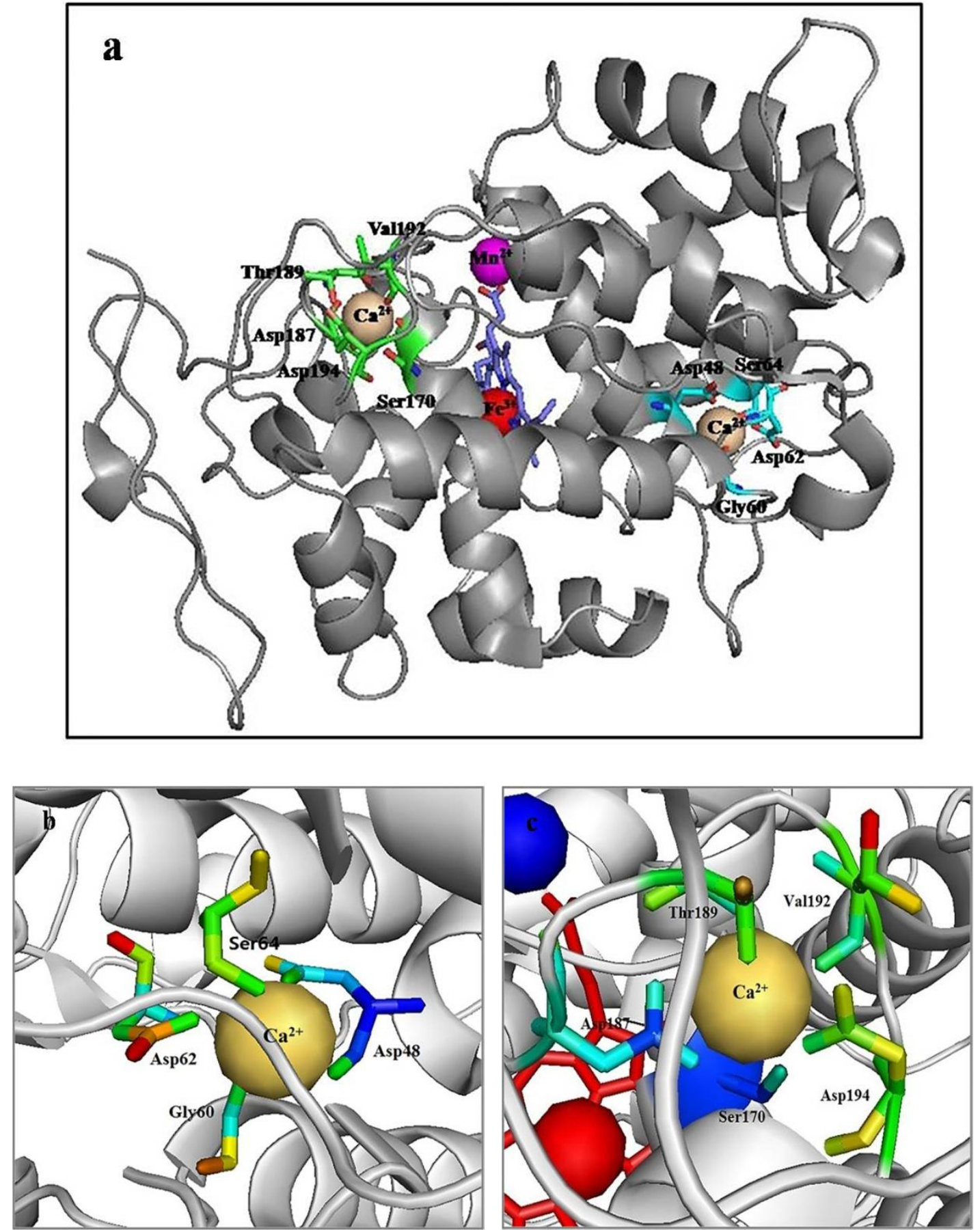
Fig. 2

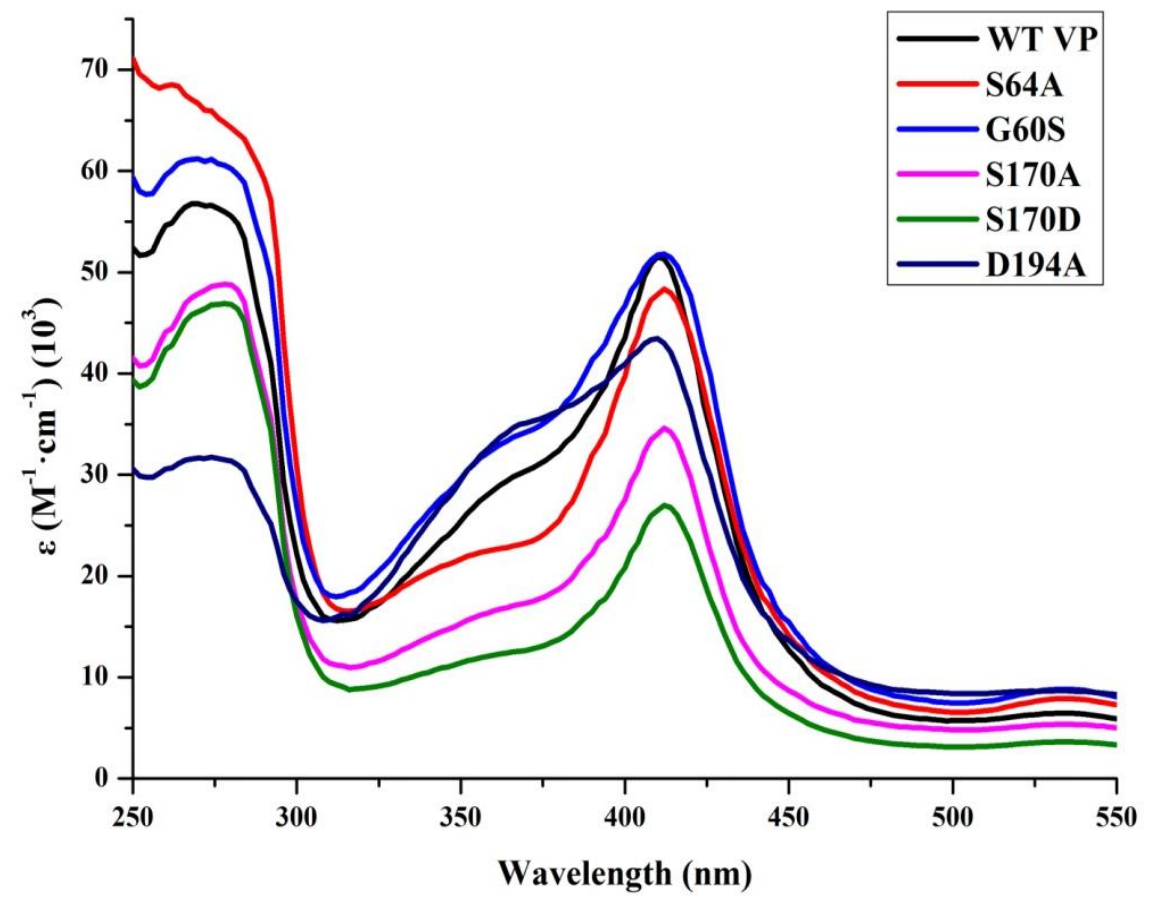


Fig. 3
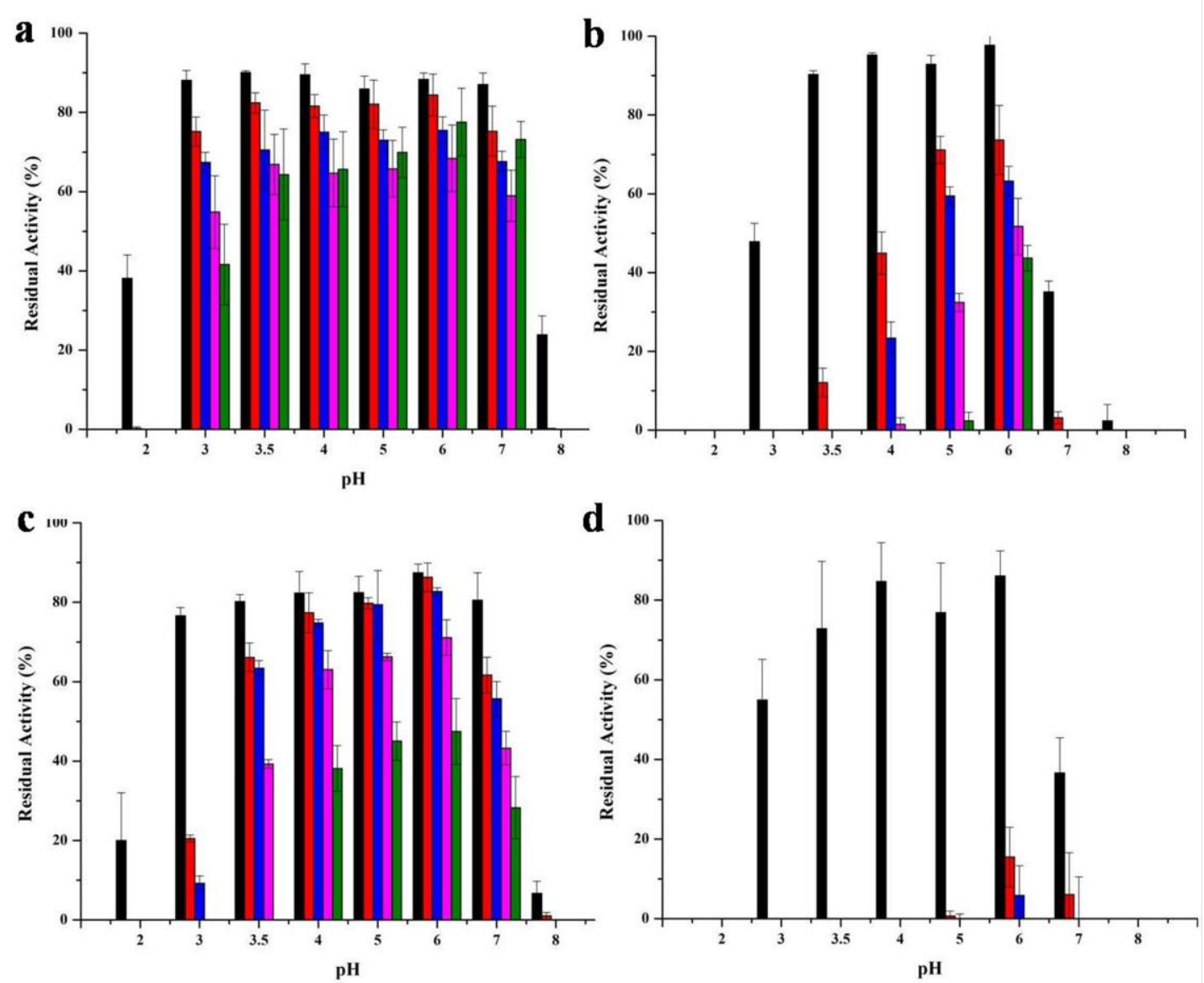
Fig. 4

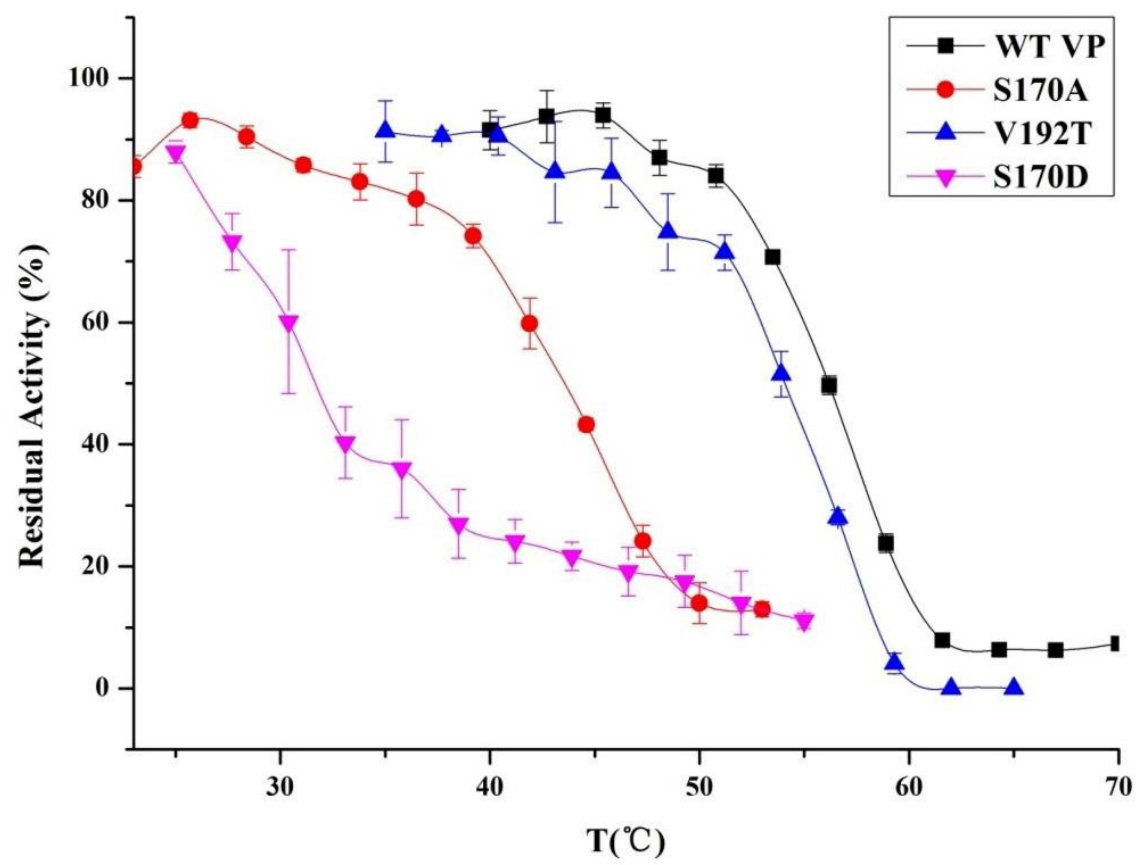


Fig. 5

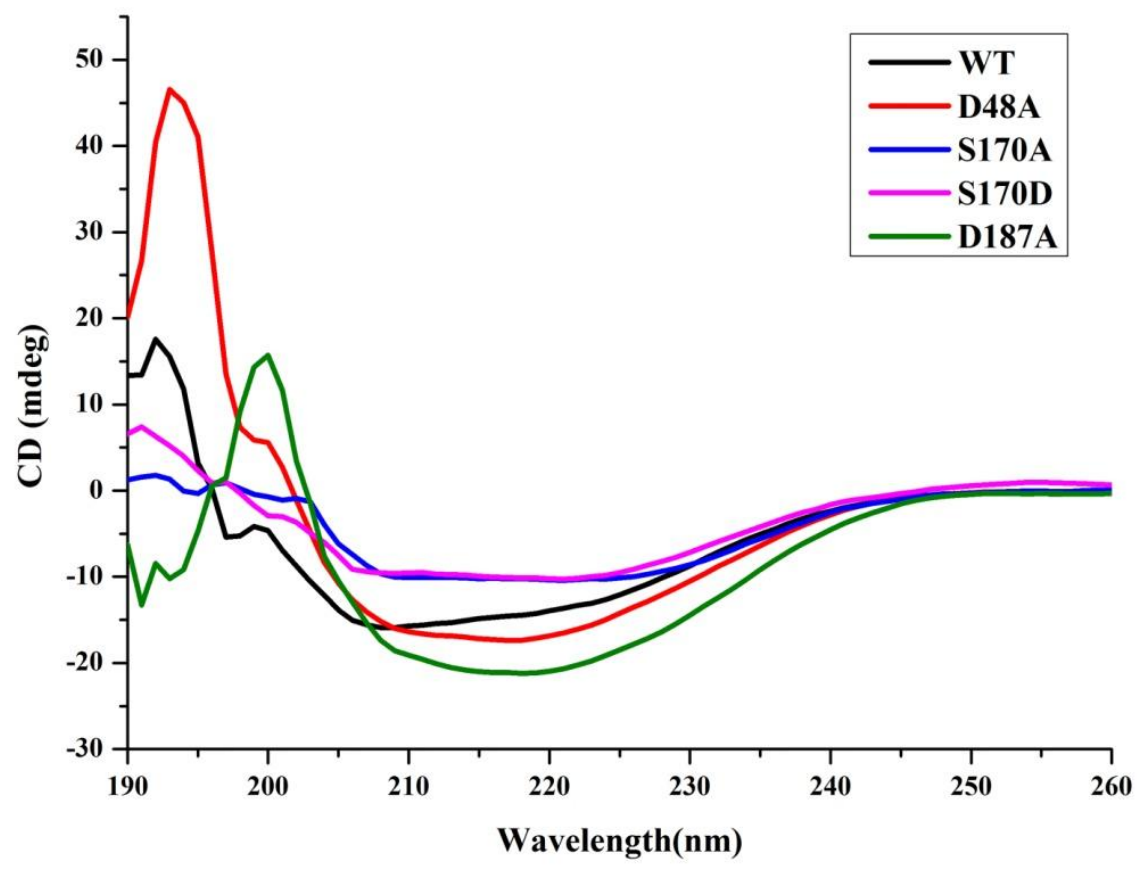

